\title{
Homelessness, emergency care and mental health. Inner-city emergency department psychiatry referrals: a retrospective descriptive analysis
}

\author{
Aoibheann Mcloughlin ${ }^{1}$ (D) $\cdot$ Anna Feeney ${ }^{1} \cdot$ John Cooney $^{2}$ \\ Received: 10 May 2020 / Accepted: 24 September 2020 / Published online: 1 October 2020 \\ (C) Royal Academy of Medicine in Ireland 2020, corrected publication 2020
}

\section{Introduction}

Since the advent of COVID-19, the vulnerability of people who are homeless has come into sharper focus. The risk posed by sleeping rough or staying in emergency/temporary accommodation exposes homeless people to a high risk of transmission due to compromised access to isolation spaces and adequate hygiene facilities [1]. This situation is compounded by the fact that homeless people are a medically at-risk population more likely to become seriously ill and to experience health inequities across a broad spectrum of health conditions $[1,2]$. Worldwide, homeless groups encounter markedly disproportionate mortality rates relative to general, housed, or low-income populations [3-6].

In Ireland, findings from a 5-year study of a cohort of homeless people in Dublin found that the standard mortality rate was 6-10 times higher in homeless women and 3-10 times higher in homeless men when compared with the general population [3]. In line with increased physical morbidity, homeless people are significantly more likely to have drug and alcohol dependence than the general population in Western countries. The prevalence of psychiatric disorders is also elevated [7], and although there is significant heterogeneity between studies, meta-regression analysis shows an increased prevalence of personality disorder and psychotic illness in homeless studies [8]. Furthermore, homeless populations with a history of a psychiatric order represent a high-risk group of death by unintentional injury and suicide [9].

High rates of homelessness among the mentally ill have already been identified in the Irish remand prison context. In

Aoibheann Mcloughlin

aoibheannmcloughlin@gmail.com

1 Psychiatry Registrar, St. Patrick's Hospital, Dublin 8, Ireland

2 St. James's Hospital, Dublin 8, Ireland a recent study of 3 years of committals to the main Irish remand prison, $35 \%$ of all episodes taken on to the psychiatric service caseload were homeless between 2012 and 2014 [10]. This figure represented an increase from 2006 to 2011, when $23.4 \%$ of this service's caseload were classed as homeless [11].

Homelessness has now reached a crisis point in Ireland. In July 2019 , there were 10,275 people officially documented as homeless nationwide, with 6497 adults and 3778 children accessing state-funded emergency accommodation during this time [12]. This represents more than a doubling of those seeking emergency shelter over the past 6 years (see Fig. 1). However, these numbers may under-estimate the extent of homelessness as they do not represent those sleeping rough, in direct provision centres, domestic violence refuges, couch surfing, or homeless people in hospitals or prisons [13].

The majority of homeless people $(66 \%)$ in Ireland are located in the Dublin area [12]. Currently, there are two homeless-specific psychiatry services in Dublin; the ACCES and Northside Teams. However, given the high numbers of homeless people requiring psychiatric intervention, these services are potentially under-resourced to meet rising need.

\section{Results}

Across Dublin south city, St. James's Hospital (SJH) provides psychiatric care to a population of 136,704 people within areas of significant deprivation [14]. During the month of the study (March 2019), 4315 adults accessed emergency homeless accommodation in Dublin [15]. Of the 109 psychiatry referrals received through the Emergency Department at SJH during this time, over a quarter $(n=30,28 \%)$ of people reported themselves to be homeless or living in temporary accommodation. An additional 5\% were documented as living in permanent residential or sheltered care and so were not included in the study. 
Fig. 1 Number of adults accessing emergency homeless accommodation in Ireland over a 6-year period

\section{Number of Adults Accessing Emergency Homeless \\ Accommodation in Ireland over a 6-year Period}

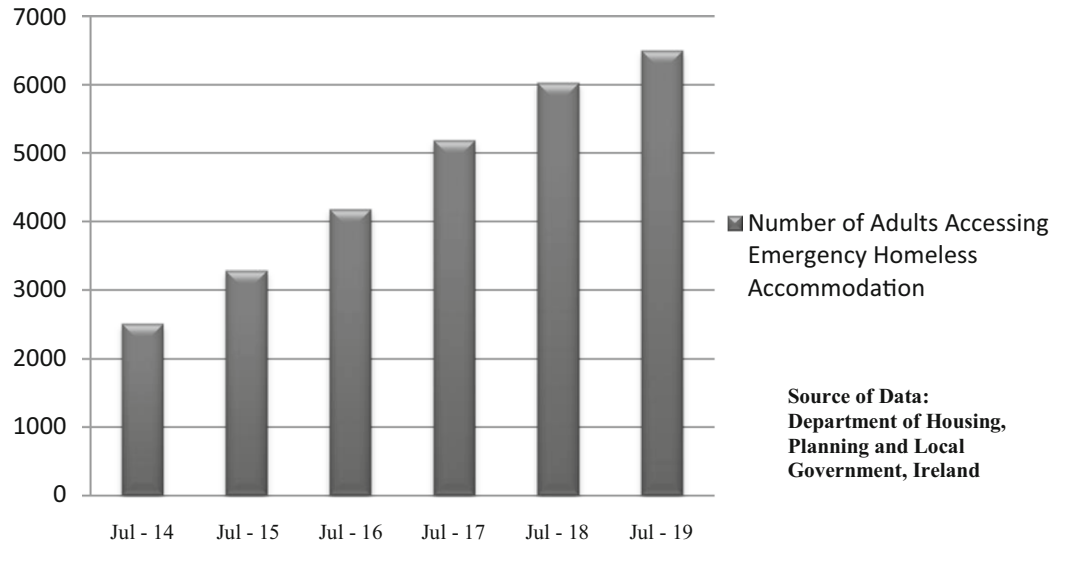

A higher proportion of male presenters (26/30) was evidenced in the homeless sample of psychiatric referrals $(86.7 \%)$, as opposed to $62 / 109(56.9 \%)$ of the general referral sample. In contrast, four of the thirty homeless presenters were female $(13.3 \%)$. This represents a reduced presence from the $47 / 109(43.1 \%)$ total of females referred overall. The most frequently represented group of overall referrals were Irish, unemployed males and females between the age of 20 and 29 years old. In the homeless cohort, the most frequently represented group were Irish, unemployed males between the ages of 20 and 29 (12/30).

Relationship status was also recorded in the total sample. In the 28 of 30 homeless presenters who elected to discuss their relationship status, 27 of $28(96.4 \%)$ reported that they were not currently in a relationship. In the total sample, 107 of 109 indicated their relationship status. Of those, 82 of the 107 $(76.6 \%)$ were not in a romantic relationship at time of presentation. All of the referred homeless patients were unemployed ( $n=30$ ) versus $69.1 \%$ of the housed sample.

Following triage by the emergency department clinicians, $50 \%$ of homeless patients were referred to psychiatry following expressed thoughts or acts of self-harm, categorised as "suicidal behaviour". In comparison, a higher percentage of the housed sample of referrals $(58 \%)$ presented with documented suicidal behaviour. Illicit drug abuse/dependence was associated with $73 \%$ of referrals involving homeless presenters, as opposed to $53 \%$ in the housed sample. Most frequently used illicit drugs were as follows: opiates (heroin and street methadone), cocaine, cannabis, and benzodiazepines. Alcohol abuse/dependence was associated with $47 \%$ of referrals of homeless people, and represented an elevation from the $39 \%$ recorded in the housed sample.

Following psychiatric evaluation by on-call or liaison psychiatry clinicians, under a quarter $(23 \%)$ of homeless patients were assessed as having a major mental illness (affective or psychotic disorder), and in most of these cases, illicit drug and alcohol abuse were compounding factors in exacerbating symptomatology. In the housed sample, a higher total of $32 \%$ of presenters referred to psychiatry were assessed as experiencing major mental illness. Vulnerable personality traits in the setting of substance misuse accounted for the majority of diagnoses in homeless people $(67 \%)$.

Of those referred, $66 \%$ had previously been reviewed by psychiatry during prior ED presentations and $60 \%$ of homeless presenters reported that they had previously been, or were currently linked in with community mental health teams. Over $67 \%$ ( $n=19$ out of 28 documented) of homeless people referred to psychiatry had previously been admitted once or more to a hospital psychiatric unit.

\section{Discussion}

Ireland is in the midst of an escalating homeless crisis, as evidenced by exponentially rising homeless figures (see Fig. 1). A significant number of homeless people with mental illness are currently supported within Irish prisons and hospitals. This study illustrates the impact of the homeless crisis as reflected in the volume of referrals received by psychiatry during the course of a month.

In accordance with the finding that alcohol dependency and active drug use is reported to be highly prevalent in the Irish homeless population [16], a significant number of this study's homeless presenters endorsed drug and alcohol abuse. This exceeded that of the housed comparison. In relation to major affective or psychotic illness, the homeless cohort in this study was found to have a lower rate of assessed psychiatric disorder than their housed contemporaries. 
Ten years ago, research on admissions to a Dublin hospital evaluated that homeless people were over-represented in the accident and emergency department due to the fact that their psychological and medical needs were not being met in primary care [17]. The route to healthcare is not always straightforward. Almost half of homeless people in Dublin were previously found to have no medical card for free medical care and prescriptions [17] complicating access to primary care. The financial implication of having to pay for a primary care consultation was seen to drive a tendency to bypass primary care and attend the emergency department for treatment [18]. Medical card acquisition is complicated by problems accessing information on entitlements and benefits, having no address, and difficulties completing the necessary forms. However, in recent years, medical card access for homeless people has improved significantly to $77 \%$ (over half that of the general population), as has access to GP care; as reflected by registration rates [6]; which highlights efforts of homeless services to tackle this issue. Yet, from 1997 to 2013, the rate of accident and emergency attenders among the homeless population continued to rise steadily, in concordance with an observed increase in drug use over time [6]. This suggests that increased access to primary care services is in fact not preventing utilisation of acute secondary care services, and is complicated by the sequelae of increased drug use [6].

Over two thirds of homeless people referred to psychiatry in this study were previously hospitalised in a specialist psychiatric unit, representing an increase of $25 \%$ from that of the housed cohort. In a cross-sectional survey of homeless people in Dublin $(n=538)$ and Limerick $(n=63)$ in 2013 [6], respondents who attended the accident and emergency department were three times as likely to have previously attended a specialist psychiatric hospital service. Moreover, people who were linked in with homeless services were twice as likely to have attended a psychiatric hospital service within the previous 6 months [6]. The fact that $66 \%$ of the people referred in this study were previously assessed by psychiatry via the SJH Emergency Department highlights the chronic physical and mental health sequelae that arise when a person experiences homelessness. Of the sample referred to psychiatry, $60 \%$ reported that they had been, or were, currently linked in with specialist community mental health services, reflecting difficulties in access, service delivery, and engagement.

Homeless people are more likely to be hospitalised than the housed population, but on-going and long-term engagement with planned health services [18] continues to be poor. Navigating the precarious life of homelessness requires so much energy that basic survival, shelter, and sustenance needs may be prioritised over seeking treatment. Keeping in contact with service providers can be a challenge, especially for individuals with dual diagnoses. This fact was underlined by a study showing that mentally ill alcohol dependent homeless people were 5 times more likely to lose contact with caring agencies than homeless people with mental disorders who were not dependent on alcohol [19]. It is apparent that this lack of engagement and compliance can be a source of disillusionment to mental health service providers. As such, it is important that services adapt to needs identified by homeless people to promote as much engagement as possible.

The findings in this study highlight unemployment for homeless presenters, as access to jobs are obstructed by lack of address, literacy issues, and psychosocial factors. With the exception of one case, the entire homeless sample reported that they were not in a current relationship. Frequently, homeless people lack social capital and support that might act as a buffering factor in helping to ameliorate stress factors. (An issue highlighted by an Irish study where $47 \%$ of homeless respondents had no close relatives and $37 \%$ had no close friends that they could approach when they required support.) [20].

Homelessness is caused by an interaction between individual, societal/familial, and structural factors. At an individual level, poverty, substance misuse, and mental health problems, in the context of reduced social/family supports, combined with structural factors such as a lack of access to affordable housing contribute towards homelessness [21]. Homelessness, and its inherent marginalisation, engenders a loss of safety, privacy, belonging, agency, and autonomy that renders an individual especially susceptible to ill-health. It is evident that homelessness compounds the effects of mental health difficulties and vice versa, rendering vulnerable individuals more psychologically exposed. Given the aforementioned, it is unsurprising that people with mental illness tend to remain homeless longer than people without [22].

\section{Conclusion}

Findings from this study strongly reflects Dublin city's current 'homeless crisis' as evidenced by the high proportion of homeless people referred for psychiatric assessment via the emergency department. The acute and long-term physical and psychological sequelae of COVID-19 for this very vulnerable at-risk group give rise for concern.

In this study, the majority of individuals with no fixed abode were assessed as having concomitant substance misuse and personality difficulties, and had, on previous occasions, been reviewed by psychiatry services or admitted to psychiatric units. The high prevalence of substance misuse echoes that of international research. Polysubstance abuse, vulnerable personality traits, unemployment, social isolation, poor physical health, and lack of continued engagement with planned healthcare services are factors leading to significant mental distress for homeless patients referred for psychiatric assessment in this study. 
The high proportion of patients reporting to be homeless suggests the need for a renewed impetus into devising tailored and flexible multi-disciplinary assessments and interventions at ED and primary care levels. Frequently, vulnerable patients most in need of integrated care, such as homeless people with addiction issues, are obscured from accessing continuing supports. Mental healthcare delivery demands a different approach, which works with homeless stakeholders and primary care in enabling better utilisation of services. More research is needed to explore what form this delivery will take.

Contributions Dr. Aoibheann McLoughlin is the lead author.

Dr. Anna Feeney is the second author.

Dr. John Cooney is the study supervisor.

\section{Compliance with ethical standards}

Conflict of interest The authors declare that they have no conflicts of interest.

Ethical standards The authors assert that all procedures contributing to this work comply with the ethical standards of the relevant national and institutional committee on human experimentation with the Helsinki Declaration of 1975, as revised in 2008.

This Study was approved as a Quality Improvement initiative by the Joint Research and Ethics Committee of St. James's Hospital and Tallaght University Hospital on the 5th of June 2019.

\section{References}

1. European Federation of National Associations Working with the Homeless (FEANTSA) COVID-19: "Staying home" not an option for people experiencing homelessness. Accessed $18^{\text {th }}$ March 2020. Available from: https://www.feantsa.org/en/news/2020/03/18/ covid19-staying-home-not-an-option-for-people-experiencinghomelessness

2. Aldridge RW, Story A, Hwang SW et al (2018) Morbidity and mortality in homeless individuals, prisoners, sex workers, and individuals with substance use disorders in high-income countries: a systematic review and meta-analysis. Lancet. 391(10117):241-250

3. Ivers J-H, Zgaga L, O’Donoghue-Hynes B et al (2019) Five-year standardised mortality ratios in a cohort of homeless people in Dublin. BMJ Open 9(1):e023010

4. Hwang SW, Wilkins R, Tjepkema M et al (2009) Mortality among residents of shelters, rooming houses, and hotels in Canada: 11 year follow-up study. BMJ 339:b4036

5. Morrison DS (2009) Homelessness as an independent risk factor for mortality: results from a retrospective cohort study. Int J Epidemiol 38(3):877-883

6. O' Reilly F, Barror S, Hannigan A, et al (2015) Homelessness - an unhealthy state: health status, risk behaviours and service utilisation among homeless people in two Irish cities. The Partnership for Health Equity, Dublin.
7. Nilsson SF, Hjorthøj CR, Erlangsen A, Nordentoft M (2011) Psychiatric disorders and mortality among people in homeless shelters in Denmark: a nationwide register-based cohort study. Lancet. 377:2205-2214

8. Fazel S, Khosla V, Doll H, Geddes J (2008) The prevalence of mental disorders among the homeless in western countries: systematic review and meta-regression analysis. PLoS Med 5(12):e225

9. Nilsson SF, Hjorthøj CR, Erlangsen A, Nordentoft M (2014) Suicide and unintentional injury mortality among homeless people: a Danish nationwide register-based cohort study. Eur J Pub Health 24:50-56

10. O'Neill C, Smith D, Caddow M et al (2016) STRESS-testing clinical activity and outcomes for a combined prison in-reach and court liaison service: a 3-year observational study of 6177 consecutive male remands. Int J Ment Health Syst. 10:67

11. McInerney C, Davoren M, Flynn G et al (2013) Implementing a court diversion and liaison scheme in a remand prison by systematic screening of new receptions: a 6 year participatory action research study of 20,084 consecutive male remands. Int J Ment Health Syst $7: 18$

12. Department of Housing, Planning \& Local Government Homelessness Report July 2019. [Retrieved from: https://www. housing.gov.ie/homeless-report-july-2019]. Accessed 22 Sept 2019

13. Peter McVerry Trust. Facts and figures. Information on homelessness in Ireland. [Retrieved from https://pmvtrust.ie/news/facts-andfigures/]. Accessed 22 Sept 2019

14. Pobal HP Deprivation Index. Updated 8th September 2017. [Available from https://maps.pobal.ie/WebApps/ DeprivationIndices/index.html]. Accessed 22 Sept 2019

15. Department of Housing, Planning \& Local Government Homelessness Report March 2019. [Retrieved from: https://www. housing.gov.ie/housing/homelessness/homeless-report-march2019]. Accessed 22 Sept 2019

16. Lawless M, Corr C (2005) Drug use among the homeless population in Ireland. A report for the National Advisory Committee on Drugs. National Advisory Committee on Drugs \& Merchants Quay Ireland. The Stationery Office, Dublin.

17. Casey P, O'Neill A, Minton R (2007) The homeless mentally ill: an audit from an inner city hospital. Ir J Psychol Med 24(2):62-66

18. Holohan T (1997) Health status, health service utilisation and barriers to health service utilisation among the adult homeless population of Dublin. Eastern Health Board, Dublin

19. Marshall M, Nehring J, Taylor C, Gath D (1994) Characteristics of homeless mentally ill people who lose contact with caring agencies. Ir J Psychol Med 11(4):160-163

20. Feeney A, McGee H, Holohan T, Shannon W (2000) Health of hostel-dwelling men in Dublin. Royal College of Surgeons in Ireland and Eastern Health Board, Dublin

21. Fazel S, Geddes JR, Kushel M (2014) The health of homeless people in high-income countries: descriptive epidemiology, health consequences, and clinical and policy recommendations. Lancet. 384(9953):1529-1540

22. National Coalition for the Homeless (2006) Mental illness and homelessness. NCH Fact Sheet \#5 June 2006. National Coalition for the Homeless, Washington.

Publisher's note Springer Nature remains neutral with regard to jurisdictional claims in published maps and institutional affiliations. 